Received: 22 January 2019

Accepted: 4 June 2019

Published online: 25 June 2019
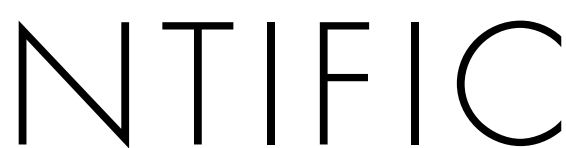

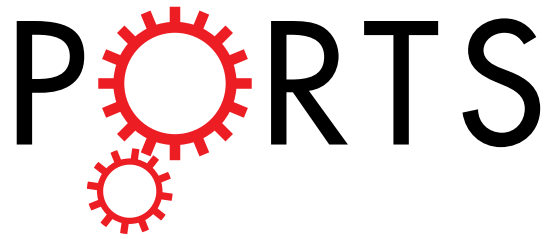

\title{
OPEN
}

\section{The three-hybrid genetic} composition of an Ecuadorian population using AIMs-InDels compared with autosomes, mitochondrial DNA and $Y$

\section{chromosome data}

\author{
Ana Karina Zambrano $\mathbb{D}^{1}$, Aníbal Gaviria², Santiago Cobos-Navarrete ${ }^{2}$, Carmen Gruezo ${ }^{2}$, \\ Cristina Rodríguez-Pollit ${ }^{2}$, Isaac Armendáriz-Castillo $\mathbb{D}^{1}{ }^{1}$, Jennyfer M. García-Cárdenas $\mathbb{D}^{1}$, \\ Santiago Guerrero $\mathbb{1}^{1}{ }^{1}$, Andrés López-Cortés ${ }^{1}$, Paola E. Leone ${ }^{1}$, Andy Pérez-Villa $\mathbb{1}^{1}{ }^{1}$, \\ Patricia Guevara-Ramírez ${ }^{1}$, Verónica Yumiceba ${ }^{1}{ }^{1}$, Gisella Fiallos ${ }^{2}$, Margarita Vela ${ }^{2}$ \& \\ César Paz-y-Miño (i) ${ }^{1}$
}

The history of Ecuador was marked by the arrival of Europeans with Africans, resulting in the mixture of Native Americans with Africans and Europeans. The present study contributes to the knowledge of the Ecuadorian mestizo population by offering information about ancestry and ethnic heterogeneity. Forty-six AIM-InDels (Ancestry Informative Insertion/Deletion Markers) were used to obtain information on 240 Ecuadorian individuals from three regions (Amazonia, the Highlands, and the Coast). As a result, the population involved a significant contribution from Native Americans (values up to $51 \%$ ), followed by Europeans (values up to $33 \%$ ) and Africans (values up to $13 \%$ ). Furthermore, we compared the data obtained with nine previously reported scientific articles on autosomal, mitochondrial DNA and $Y$ chromosomes. The admixture results correspond to Ecuador's historical background and vary slightly between regions.

The origin of men in America begins with their arrival from Asia by the Bering Strait, which started forty or fifty thousand years before Christ ${ }^{1}$. Specifically, in "Ecuatorial Andinoamérica" (known today as Ecuador), there is evidence of settlement from twelve thousand years ago ${ }^{1}$. American history continues with the arrival of Europeans (Spanish) to the continent, in which African descendants were brought as slaves ${ }^{2}$. Consequently, the Spaniards took control of the Panama Isthmus and then started to travel south. The first conquer and colonization expedition to Ecuador was in 1526. They arrived at the coast where they disembarked to go inland ${ }^{1}$.

In addition, slaves arrived from Africa to Europe due to the slave trade, in addition to Muslim and Portuguese as merchants, since the Middle Ages. As a result, the slaves who came to America constituted a heterogeneous group from different societies and cultures ${ }^{3,4}$.

For approximately twelve thousand years, the lands that are now known as Ecuador have been populated by indigenous people from Asia and Oceania. Nonetheless, after the conquering, the Spanish brought their language and customs, and the population started mixing between the natives and the Spanish and the African slaves, resulting in diversity in the Ecuadorian population ${ }^{5}$.

${ }^{1}$ Centro de Investigación Genética y Genómica, Facultad de Ciencias de la Salud Eugenio Espejo, Universidad UTE, Av. Mariscal Sucre and Mariana de Jesús, Block I, Quito, 170129, Ecuador. ${ }^{2}$ Laboratorio de Genética, Centros Médicos Especializados Cruz Roja Ecuatoriana, Papallacta oe1-66, Quito, 170512, Ecuador. Ana Karina Zambrano and Aníbal Gaviria contributed equally. Correspondence and requests for materials should be addressed to C.P.-y. (email: cesar. pazymino@ute.edu.ec) 
The census in Ecuador that began in 1950 classified people by asking for certain characteristics, such as language, and tried to predict the behavior of the indigenous groups ${ }^{6,7}$. The most recent census was in 2010 , and according to the results, the population projection for 2019 was an estimated 17267986 Ecuadorians, with 24 provinces distributed in 4 different regions: the Coast (8 523 453), the Highlands or the Andes (7 733 725), Amazonia (937 406), and the insular region $(32320)^{8}$. Moreover, in the census, Ecuadorians self-identified as "mestizos" 71.9\%, "montubios" 7.4\%, Afro-Ecuadorians 7.2\%, "Indígenas" $7 \%$ and "blancos" $6.1 \% 9$.

The genetic population structure of Ecuador has been previously studied using different genetic markers, such as mitochondrial DNA ${ }^{10-12}$, Y chromosome ${ }^{10,13}$ or autosomes ${ }^{14-18}$. Some of these studies are focused on Native American or Afro-Ecuadorian groups ${ }^{10-12}$, and others are focused on mestizo populations but with a sampling that did not consider the Ecuadorian regions ${ }^{14-18}$. Moreover, those reports emphasize different genetic markers, such as AIMs (Ancestry Informative Markers), that have been used to fully understand the differentiation (ancestral or geographical) across populations, which can also infer migration, admixture, colonization, and/or invasion events ${ }^{19}$. Here, we report genetic data of the Ecuadorian mestizo population using AIMs-InDels. In addition, we analyzed and compared the data with previously reported data of the genetic ancestry of the Ecuadorian population.

\section{Materials and Methods}

Sample collection and DNA extraction. A total of 240 unrelated self-identified mestizo samples were randomly selected (53 from all of the provinces in Amazonia, 88 from all of the provinces in the Highlands, and 99 from all of the provinces on the Coast). All individuals signed the informed consent form for population genetic studies. Blood samples were collected on FTA paper (GE Healthcare Life Sciences) at the Genetic Laboratory of Centros Médicos Especializados Cruz Roja Ecuatoriana.

DNA was extracted using Chelex 100 (Bio-Rad) (20\%) according to the standardized method of the Genetic Laboratory based on the method published by the President's DNA Initiative $e^{20}$ protocol, with a modification in the concentration of Chelex used (20\%).

All methods were carried out in accordance with relevant guidelines and regulation ${ }^{21}$. Moreover, the experimental protocols were approved with the number 2018-127E by "Comité de Ética de Investigación en Seres Humanos Universidad San Francisco de Quito".

Amplification and genotyping. PCR amplification of the 46 AIM-InDels was performed with the same primers and one multiplex reaction, according to Pereira et al. ${ }^{22}$. Fragment separation and detection were executed on the ABI PRISM 3100, 3130 and 3500 Genetic Analyzers (Applied Biosystems). The results were collected with Data Collection v2.0 and v4.0 and analyzed by Gene Mapper v3.2 and v5 (Applied Biosystems). Along with the samples, to evaluate the amplification efficiency during the PCR and the genotyping steps, positive controls were used (male DNA control $007^{23}$, female DNA control $9947 \mathrm{~A}^{24}$ and random references samples from GHEP ${ }^{25}$ quality control to evaluate the amplification process), and one negative control was used to test for contamination. Short alleles were coded as 1 , while long alleles were coded as 2 .

Statistical analyses. The population genetic parameters (allele frequencies, Hardy-Weinberg equilibrium, and $\mathrm{F}_{\mathrm{ST}}$ genetic distances) were estimated using Arlequin v3.5.2.2 $2^{26}$. With STATISTICA v.1327, an multidimensional scaling (MDS) scatterplot was constructed to visualize the genetic distances between Ecuador and each reference population from HGDP-CEPH (Africans, Europeans and Native Americans) subset H952 ${ }^{21,28,29}$. Once the allele frequencies were obtained, the allele frequency differentials $(\delta)$ were estimated by comparing the frequencies reported by Pereira et al..$^{22}$ from Native Americans, Europeans, and Africans due to the historical background of Ecuador.

Ancestry inferences were made using STRUCTURE v2.3. $4^{30}$; the runs consisted of a burn-in length of 5000 followed by 5000 Markov Chain Monte Carlo (MCMC) interactions. The option used was the admixture model ("Use population information to test for migrants"). Moreover, three repetitions were performed to estimate the cluster used, and the $\mathrm{k}$ value was tested from $\mathrm{K}=1$ to $\mathrm{K}=20$ to evaluate the $\mathrm{Ln}$ probability of data ( $\mathrm{LnP}(\mathrm{D})$ ) by plotting it according to Evanno et al. ${ }^{31}$. Finally, principal component analysis (PCA) was performed to visualize the population structure: the relationship between the Ecuadorian population and the reference population used $^{32}$. RStudio v1 $0.44^{33}$ was used to obtain the PCA plot and the variance in the two first principal components.

Comparative analysis with previously reported data. An exhaustive study was performed to compare the present study with the results obtained in previous reported studies that used autosomes, Y chromosome or mitochondrial DNA related to the origin of the Ecuadorian population. Table 1 shows the previously reported data that are used in the current work.

\section{Results}

Population genetic parameters. Allele frequencies for short alleles (1) and long alleles (2) were estimated for the 240 samples from the three regions (Amazonia (AM), Highlands (HL), Coast (CO)) and joined as Ecuador (ECU). Moreover, observed and expected heterozygosities were calculated for Ecuador, in which the marker with the highest variability was MID-397 (0.551). Allele frequency differentials $(\delta)$ were estimated for Ecuador against each reference population (Africans, Europeans and Native Americans), resulting in a differential average of 0.320 with Africans, 0.196 with Europeans, and 0.12 with Native Americans. As expected, Ecuador has a similar level of diversity with the reference Native American population. Furthermore, allele frequency differentials $(\delta)$ were also estimated between regions, showing a low allele frequency differential mean (0.045 Amazonia-Highland; 0.071 Amazonia-Coast; 0.055 Highland-Coast) that increased when the geographical distance increased. (Table S1)

Once the Bonferroni correction $(\mathrm{p}>0.001)$ was applied, no significant deviations from Hardy-Weinberg equilibrium were found for the 46 loci in the population under study. Moreover, linkage disequilibrium 


\begin{tabular}{|l|l|l|l|}
\hline Genetic markers used & $\begin{array}{l}\text { Population } \\
\text { under study }\end{array}$ & $\begin{array}{l}\text { Total } \\
\text { number of } \\
\text { populations }\end{array}$ & Reference \\
\hline Mitochondrial DNA & Waoranis & 36 & 10 \\
\hline Mitochondrial DNA & $\begin{array}{l}\text { Kichwas and } \\
\text { Mestizos }\end{array}$ & 107 & 11 \\
\hline Mitochondrial DNA & Cayapas & 204 & 12 \\
\hline Y- STRs & Mestizos & 415 & 13 \\
\hline Autosomal AIMs & $\begin{array}{l}\text { Mestizo, } \\
\text { Kichwas, } \\
\text { Afro- } \\
\text { Ecuadorians }\end{array}$ & 162 & 14 \\
\hline Autosomal AIMs-InDels & Mestizos & 171 & 15 \\
\hline Autosomal SNPs & $\begin{array}{l}\text { Kichwas and } \\
\text { Mestizos }\end{array}$ & 119 & 16 \\
\hline Autosomal SNPs & Mestizos & 19 & 17 \\
\hline Autosomal SNPs & Mestizos & 6 & 18 \\
\hline
\end{tabular}

Table 1. Genetic markers, populations and references used in the review of origin of Ecuadorians.

\begin{tabular}{|l|l|l|l|l|l|l|l|}
\hline & & Amazonia & Highland & Coast & Africa & Europe & $\begin{array}{l}\text { Native } \\
\text { America }\end{array}$ \\
\hline \multirow{4}{*}{ Ecuador } & Amazonia & - & 0.0201 & $<5 \mathrm{e}-05$ & $<5 \mathrm{e}-05$ & $<5 \mathrm{e}-05$ & $<5 \mathrm{e}-05$ \\
\cline { 2 - 8 } & Highland & 0.00279 & - & $<5 \mathrm{e}-05$ & $<5 \mathrm{e}-05$ & $<5 \mathrm{e}-05$ & $<5 \mathrm{e}-05$ \\
\cline { 2 - 8 } & Coast & 0.01220 & 0.00666 & - & $<5 \mathrm{e}-05$ & $<5 \mathrm{e}-05$ & $<5 \mathrm{e}-05$ \\
\hline \multirow{3}{*}{ Reference } & Africa & 0.35975 & 0.34842 & 0.28422 & - & $<5 \mathrm{e}-05$ & $<5 \mathrm{e}-05$ \\
\cline { 2 - 8 } & Europe & 0.16233 & 0.15013 & 0.11830 & 0.36515 & - & $<5 \mathrm{e}-05$ \\
\cline { 2 - 8 } & Native America & 0.05140 & 0.05218 & 0.07399 & 0.44273 & 0.29768 & - \\
\hline
\end{tabular}

Table 2. Genetic distances $\left(\mathrm{F}_{\mathrm{ST}}\right)$ between the Ecuadorian population (Amazonia, the Highlands, and the Coast) and the reference population (Africa, Europe and Native America) (lower diagonal) and P values (upper diagonal).

$(\alpha>4.6 \times 10-5)$ did not show any significant associations between the markers, except for MID-225 and MID-94 in the Coast population, but not in the other two populations. That result suggests that there is not a real association between the markers, allowing the use of the migration model in STRUCTURE analysis ${ }^{34}$.

Genetic distances. The data obtained from the Ecuadorian population were used to estimate the $\mathrm{F}_{\mathrm{ST}}$ (Table 2) genetic distances between all population pairs.

The pairwise genetic distances showed significant differentiation between all Ecuadorian samples and the reference population and between Ecuadorian regions. To interpret the genetic distances obtained, we used the suggested values classification of Ballaux et al. (2002). Values between 0-0.05 indicate little genetic distance, 0.05 and 0.15 indicate moderate differentiation and 0.15 and 0.25 indicate great differentiation, and values up to 0.25 indicate very great differentiation ${ }^{35}$. In the present study, there is a small genetic distance between all the Ecuadorian regions (Amazonia-Highland, Amazonia-Coast and Highland-Coast). When compared with the reference population, there is a moderate differentiation between all Ecuadorian regions and the Native American population with values $<0.073$, and between the Highland and Europe populations (0.15) and the Coast and Europe populations (0.118), there is a great differentiation between African and all the Ecuadorian regions and between Europe and Amazonia. The pairwise $\mathrm{F}_{\mathrm{ST}}$ is represented in the multidimensional scaling plot in Fig. 1 to visualize the level of similarities between Ecuadorian and the reference population. In the plot, the Ecuadorian sample appears closer to the Native American reference sample.

Moreover, a population pairwise $\mathrm{F}_{\mathrm{ST}}$ was performed to obtain the genetic distances between the Ecuadorian population and available published data from the South American population. The evaluations were obtained from Colombia ${ }^{36}\left(\mathrm{~F}_{\mathrm{ST}}=0.014, \mathrm{p}<5 \mathrm{e}-05\right)$, which is located in the north border of Ecuador and Brazil ${ }^{19,37}$ $\left(\mathrm{F}_{\mathrm{ST}}=0.054, \mathrm{p}<5 \mathrm{e}-05\right)$, which is located further away. Those results showed little differentiation with Colombia and were moderately differentiated with Brazil (Fig. S1), validating the geographic distances and the difference in history of each population.

Admixture analysis. The ancestry analysis estimation is presented according to each Ecuadorian region in Fig. 2. By joining the regions as the Ecuadorian population, the composition is as follows: Native American with 59.6\%, European with 28.8\% and African with 11.6\% (Fig. 2).

STRUCTURE data analysis of the $\mathrm{Ln} P(\mathrm{D})$ by Evanno method $^{31}$ yielded $\mathrm{K}=3$ as a result. Supporting the initial inference according to the historical formation of the Ecuadorian population due to the tri-hybrid contribution of Native Americans, Europeans and Africans. 


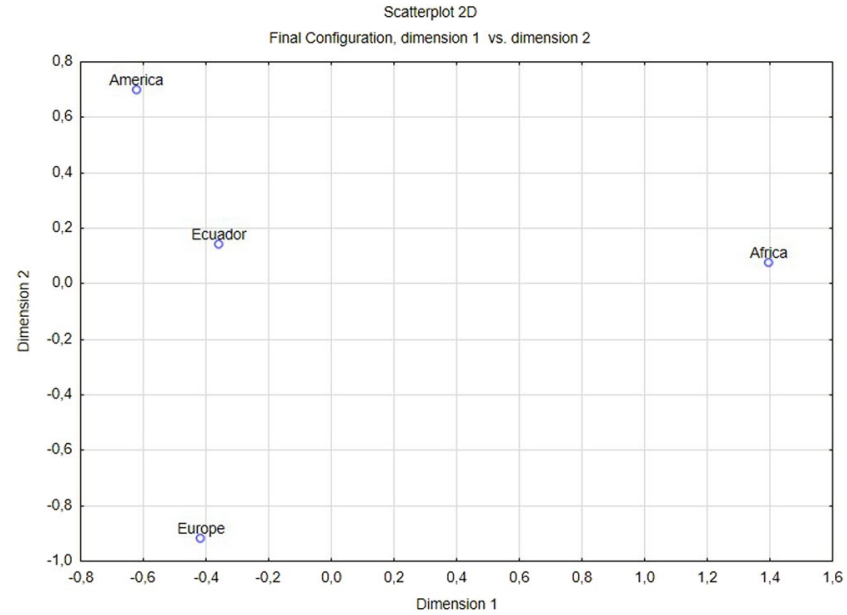

Figure 1. Multidimensional scaling plot from the $\mathrm{F}_{\mathrm{ST}}$ between the Ecuadorian population and the reference population.

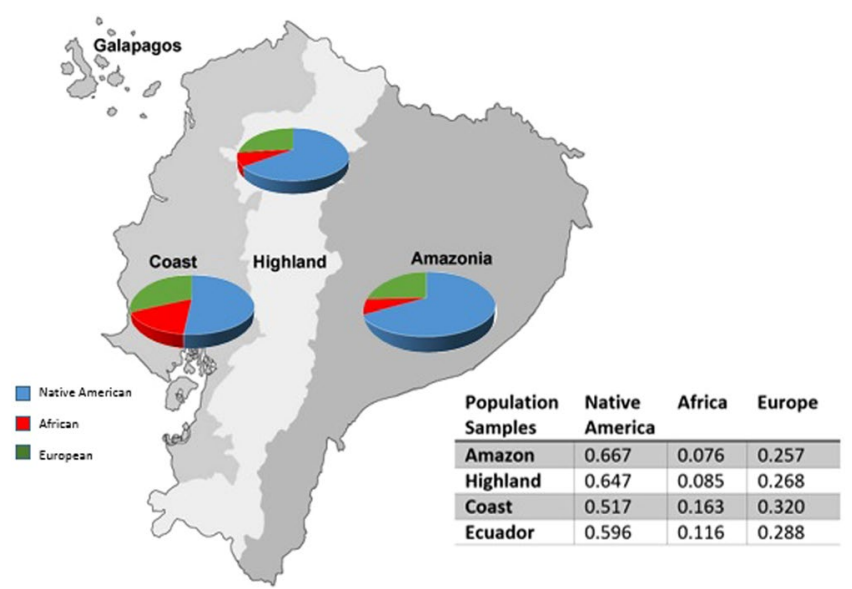

Figure 2. The proportion of Ecuadorian population origin divided into three continental regions. Values were obtained with STRUCTURE v2.3.4 $(\mathrm{k}=3$, assuming migration model).

The admixture analysis results are concordant with the genetic distances. Native American ancestry is the main composition of the mestizo Ecuadorian population, with values higher than $51 \%$. Moreover, the African contribution is the least predominant $(<16.3 \%$ in the Coast) in the analysis for the three regions (Fig. 3A).

Principal component analysis (PCA) allowed us to visualize the variance in the Ecuadorian data regarding the three reference populations (Africans in red, Europeans in green and Native Americans in blue). The two first principal components represent a total of $31.88 \%$ of the variance in the dataset and permitted a clear spatial separation of the reference population in three clusters and one cluster in the middle of Europeans and Native Americans (mainly in Native American group) representing the Ecuadorian regions (Amazonia in pink, Highlands in light blue and Coast in yellow) (Fig. 3B).

Furthermore, because we applied a random sampling with a self-identification as a mestizo, we found some individuals with a different prevalent ancestry. Figure $3 \mathrm{~B}$ shows that three Coast individuals are mainly of African ancestry; for instance, when looking at the composition, one individual has an African proportion of $82.3 \%$, a European proportion of $7.5 \%$, and a Native American proportion of $10.2 \%$. Moreover, there are some individuals from the Coast, and the Highlands are mainly located in the European cluster; as an example, looking at the composition, one individual from the Coast shows $88 \%$ European, $5.2 \%$ African, and $6.7 \%$ Native American.

Comparative analysis. After the bibliographic revision of previously reported data on the origin of the Ecuadorian population, there were nine scientific articles that used different genetic markers applied to elucidate it.

The review was based on the public scientific information, and there were a limited amount of published papers about the ancestral characterization of Ecuadorians, but while searching, we saw that there were more papers available regarding genetic markers for forensic identification purposes. Figure 4 compares the ancestral proportion in percentage of each publication found. 


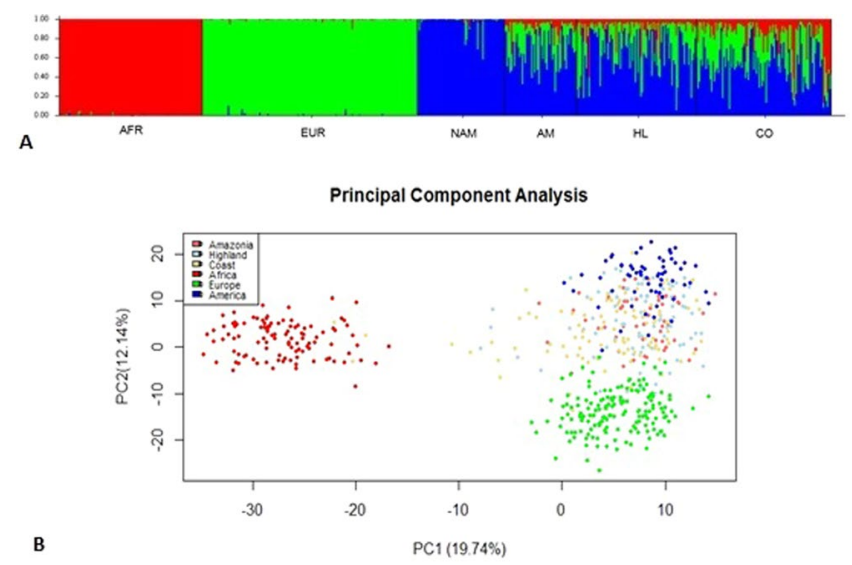

Figure 3. Admixture analysis. (A) Bar plot of the composition of the Ecuadorian population compared with the reference population (AFR: Africa; EUR: Europe, NAM: Native America, AM: Amazonia, HL: Highlands, CO: Coast) ( $\mathrm{k}=3$, assuming migration model). (B) Principal component analysis of the Ecuadorian and reference populations.

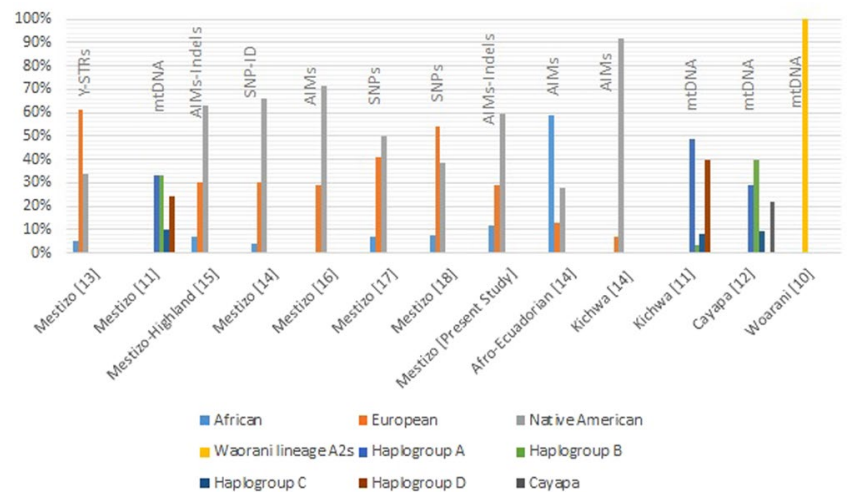

Figure 4. Comparative information of the proportions of each population with the respective method used and the reference population.

When analyzing the ancestral composition percentages, the results are heterogeneous, as shown in Fig. 4. The studies from Zambrano el al. ${ }^{15}$, Santangelo et al. ${ }^{14}$ and the present study have the closest proportions reported for African $(S D=0.039)$, Europeans $(S D=0.008)$ and Native Americans $(S D=0.031)$.

\section{Discussion}

The main objectives of this study were to infer the ancestry proportions of 240 Ecuadorian samples divided into three continental regions and to compare the results with previously reported data. To achieve this goal, we used a panel of 46 Ancestry Informative InDel markers to corroborate the advantages of their use over other commonly used genetic markers, such as SNPs: (a) the length of the InDel polymorphisms can be genotyped by fragment size separation, while SNP detection requires more complex sequencing methods ${ }^{22,38,39}$; (b) the InDels approach is easy to use and is time and cost effective, reducing the genotyping time compared with AIM-SNPs due to its potential of multiplexing by amplifying it in a single reaction $22,38,39$; (c) the workflow reduces the manipulation of samples, minimizing the number of variables that affect the results, for example, contamination risks or sample mix-ups ${ }^{22,38,39}$; (d) the potential of use in forensic genetics, such as a tool in criminal investigation, because its results could indicate the ancestry of the donor and help direct the case under analysis ${ }^{22,38,39}$.

While there are various studies on genetic markers commonly used in forensic identification analysis in Ecuador $^{40-45}$, the study of ancestral identification markers in the Ecuadorian population is underrepresented in scientific papers.

InDels showed low allele frequency differentials between Ecuadorian regions: $\delta<0.178$ among AmazoniaHighlands, $\delta<0.194$ among Amazonia-Coast and $\delta<0.14$ among Highlands-Coast. Moreover, Hardy-Weinberg analysis did not show any significance, which suggests that there is no process that affects the conditions of Hardy-Weinberg equilibrium ${ }^{46,47}$.

Additionally, the pairwise linkage disequilibrium test detected one significant association within MID2256 and MID-94 in the Coast population. Hence, while looking at the physical distance between them, it was observed that a significant distance does not exist: MID-2256 is located on chromosome 22, position $41.04 \mathrm{Mb}$; 
and MID-94 is also on chromosome 22, but in position $42.55 \mathrm{Mb}$. This linkage may occur due to the segregation caused by ancestry blocks of the mestizo population that do not allow for adequate recombination ${ }^{22,37,48}$.

The genetic distances $\mathrm{F}_{\mathrm{ST}}$ between Ecuadorian regions are low, but they are statistically significant. The $\mathrm{F}_{\mathrm{ST}}$ among Ecuadorian regions and European and African reference populations increase, while the geographic distance from the Coast increases, and the genetic distances with Native American decreases. Moreover, the ancestral characterization percentages are in accordance with the genetic distances for each region: Amazonia (66.7\% Native American, 7.6\% African and 25.7\% European), the Highlands (64.7\% Native American, 8.5\% African and 26.8\% European) and the Coast (51.7\% Native American, 16.3\% African and 32\% European). These results are concordant with the history of Ecuadorian settlement, where the Europeans arrived with African slaves along the coast to later enter the Ecuadorian territory ${ }^{1,2,5}$.

Comparing the ancestral proportions among regions, there are differences that are concordant with the history: Amazonia exhibits greater proportions of Native American origin (66.7\%) than the other two regions, which is explained by the number of different indigenous nationalities (Nacionalidad Kichua de la Amazonia, Nacionalidades Siona-Secoya, Nacionalidad A'ICofán, Nacionalidad Waorani, Nacionalidad Andora, Nacionalidad Shiwiar, Nacionalidad Zápara, Nacionalidad Shuar-Achuar and Nacionalidad Quijos) and because until the 1950s, Amazonia was habited principally by indigenous populations ${ }^{49}$. Moreover, the Coast has greater proportions of African ancestry (16.3\%) than the other Ecuadorian regions, which was elucidated by a study about an important Afro settlement in Esmeraldas that has its origins based on the arrival of African slaves in 1553 to the coast of that province and due to the group of African slaves that was brought from Colombia in the XVIII century ${ }^{49}$.

It has been reported that there is variation in the proportions of European, African and Native American ancestry among Latin America. Contrasting our results with other available data from America, a study in the Mexican population reported greater Native American ancestry $(\sim 75)^{50}$, which is consistent with the historical records of these populations. Other countries, such as Puerto Rico and the Dominican Republic, reported greater African ancestry (23.6\% and $41.8 \%$ African, respectively, SDs $12 \%$ and $16 \%$, respectively) ${ }^{18}$. In Colombia, which is located on the northern Ecuador border, heterogeneous ancestral proportions were reported depending on the region and the population under analysis, but the results of the present study show low differentiation $\left(\mathrm{F}_{\mathrm{ST}}=0.014, \mathrm{p}<5 \mathrm{e}-05\right)^{36}$. In Brazil, the results are also mixed, depending on the population, and when compared with the Ecuadorian population, it showed moderate differentiation $\left(\mathrm{F}_{\mathrm{FST}}=0.054, \mathrm{p}<5 \mathrm{e}-05\right)^{19}(\mathrm{Fig}$. S1). The differences could be explained by the geographic distances between the countries.

Additionally, comparing the results of the present study with other available data in the Ecuadorian population, it showed the following:

(1) The analysis of the $Y$ chromosome in mestizos showed a greater proportion of European ancestry (61\%), followed by Native American ancestry (34\%) and African ancestry (5\%). The results are because of male inheritance patterns of the $\mathrm{Y}$ chromosome ${ }^{13}$;

(2) Autosome analysis always shows that the Native American composition is the highest in all the studies: $59.6 \%$ (present study), $63.10 \%{ }^{15}, 65.8 \%{ }^{14}, 71.2 \%{ }^{16}, 50.10 \%{ }^{17}$ and $38.8 \%{ }^{18}$; the different percentages (SD $11.78 \%$ ) could be due to the sampling procedures because some of the reported studies did not specify the region or the sample where the population under study was from ${ }^{14-16}$. For instance, Santangelo et al. (2017) reported that the mestizo population samples were collected at a university located in Quito without specifying the geographic origin of the individuals ${ }^{14}$; another study by Poulsen et al. (2011) specified that the samples were collected in Quito, yet no individual origin is provided ${ }^{16}$.

Thus, the sampling procedure could explain the differences in percentages with the present study because we take into account all the Ecuadorian regions while they specified sampling only in Quito, which is located in the Highland region, but the studies reported an approximation with other previously reported studies of the mestizo highland population ${ }^{15}$. There were two studies using SNPs in 19 and 6 samples in which the percentage of European origin was $40.8 \%{ }^{17}$ and $53.90 \%{ }^{18}$, which is more than a $10 \%$ difference than the other publications (SD 10.78\%), 38.8\% (present study), $30.3 \%{ }^{15}, 30.1 \%{ }^{14}, 28.8 \%{ }^{16}$, which could also be explained by the sample size used of the studies because a study with a small sample size is going to estimate parameters with poor precision or be unable to detect differences between groups ${ }^{51}$. Lastly, African ancestry is similar between the studies (SD 2.7\%): $7.30 \%$ in the present study, $6.60 \%{ }^{15}, 4 \%^{14}$, $6.80 \%{ }^{17}$ and $7.30 \%{ }^{18}$. Moreover, taking into account only the papers with more than 100 individuals ${ }^{14-16}$, the standard deviation is $4.8 \%$.

(3) By using mitochondrial DNA as markers for mestizo and indigenous ancestral characterization, the results correspond to haplogroups A, B, C and D from Native American ancestry, again due to the inheritance patterns ${ }^{10-12}$.

In conclusion, our study demonstrated the use of 46 AIMs-InDels as an alternative method to measure the ancestry proportions in Ecuador and its relevant implications for understanding and corroborating the history and demography of Ecuador. The population admixture in Ecuador started with the arrival of Europeans along with African slaves; however, the Native American ancestry represents the prevalent genetic composition with more than 51\%. The autosomal AIM-InDels, mtDNA and Y chromosome information presented support the historical records with a prevalence of Native American but influenced by European (Y chromosome prevalence) and African composition.

\section{Data Availability}

The datasets generated during the current study are available from the corresponding author on request. 


\section{References}

1. Ayala-Mora, E. Resumen de Historia del Ecuador, (Corporación Editora Nacional, 2008).

2. Tinajero, A. \& Barba, A. Cronología de la Historia Resumida del Ecuador (1998).

3. Hensel, S. Africans in Spanish-America: Slavery, Freedom and Identities in the Colonial Era. Indiana 24, 15-37 (2007).

4. Borucki, A., Eltis, D. \& Wheat, D. Atlantic History and the Slave Trade to Spanish America. The American Historical Review. 120, 433-461 (2015).

5. Ayala-Mora, E. ECUADOR: PATRIA DE TODOS La nación ecuatoriana, unidad en la diversidad (2002).

6. Clark, K. Race, 'Culture,' and Mestizaje: The Statistical Construction of the Ecuadorian Nation, 1930-1950. J. Hist. Sociol. 11, 1930-1950 (1998).

7. Jorde, L. B. et al. The Distribution of Human Genetic Diversity: A Comparison of Mitochondrial, Autosomal, and Y-Chromosome Data. Am. J. Hum. Genet. 66, 979-988 (2000).

8. INEC (Instituto Nacional de Estadisticas y Censos). Proyecciones Poblacionales. Available at, http://www.ecuadorencifras.gob.ec/ proyecciones-poblacionales/, (Accessed: 11th March 2019).

9. INEC. Poster INEC. Censo de Población y Vivienda 2010 Available at, http://www.ecuadorencifras.gob.ec/censo-de-poblacion-yvivienda (2010)

10. Cardoso, S. et al. Genetic uniqueness of the Waorani tribe from the Ecuadorian Amazon. Heredity (Edinb). 108, 609-615 (2012).

11. Baeta, M. et al. Mitochondrial diversity in Amerindian Kichwa and Mestizo populations from Ecuador. Int. J. Legal Med. 126, 299-302 (2012)

12. Rickards, O., Martínez-Labarga, C., Lum, J. K., De Stefano, G. F. \& Cann, R. L. mtDNA History of the Cayapa Amerinds of Ecuador: Detection of Additional Founding Lineages for the Native American Populations. Am. J. Hum. Genet. 65, 519-530 (1999).

13. Toscanini, U. et al. The geographic mosaic of Ecuadorian Y-chromosome ancestry. Forensic Sci. Int. Genet, https://doi.org/10.1016/j. fsigen.2017.11.011 (2018).

14. Santangelo, R. et al. Analysis of ancestry informative markers in three main ethnic groups from Ecuador supports a trihybrid origin of Ecuadorians. Forensic Sci. Int. Genet. 31, 29-33 (2017).

15. Zambrano, A. K. et al. Ancestry characterization of Ecuador's Highland mestizo population using autosomal AIM-INDELs. Forensic Sci. Int. Genet. Suppl. Ser. 6, e477-e478 (2017).

16. Poulsen, L. et al. Typing of Amerindian Kichwas and Mestizos from Ecuador with the SNPforID multiplex. Forensic Sci. Int. Genet. 5, 105-107 (2011).

17. Homburger, J. R. et al. Genomic Insights into the Ancestry and Demographic History of South America. PLoS Genet. 11, 1-26 (2015).

18. Bryc, K. et al. Genome-wide patterns of population structure and admixture among Hispanic/Latino populations. Proc. Natl. Acad. Sci. 107, 8954-8961 (2010).

19. de Neves Manta, F. et al. Revisiting the Genetic Ancestry of Brazilians Using Autosomal AIM-Indels. PLoS One 8, e75145 (2013).

20. President's DNA Initiative. DNA Analyst Training. Laboratory Training Manual. Available at, https://static.training.nij.gov/labmanual/pdi_lab_userguide.pdf, (Accessed: 4th March 2017).

21. WHO. Standards and Operational Guidance for Ethics Review of Health-Related Research with Human Participants. WHO 30-45, https://doi.org/10.1111/j.1365-2958.2006.05429.x (2011).

22. Pereira, R. et al. Straightforward Inference of Ancestry and Admixture Proportions through Ancestry-Informative Insertion Deletion Multiplexing. PLoS One 7 (2012).

23. Applied Biosystems. AmpFeSTR DNA Control 007 Product Information Sheet (Pub. No. MAN0017401, Rev. A.0). Available at, www.thermofisher.com/us/en/home/global/terms-and-conditions.html, (Accessed: 4th February 2018).

24. Applied Biosystems. AmpFlSTR ${ }^{T M}$ Identifiler ${ }^{T M}$ PCR Amplification Kit User Guide (4323291 Rev. K).

25. ghep-isfg. The Spanish and Portuguese-Speaking Working Group of the International Society for Forensic Genetics. Available at, https://ghep-isfg.org/en/info/ (Accessed: 14th March 2019).

26. Excoffier, L. \& Lischer, H. E. L. Arlequin suite ver 3.5: A new series of programs to perform population genetics analyses under Linux and Windows. Molecular Ecology Resources. 10, 564-567 (2010).

27. StatSoft. Inc. STATISTICA (data analysis software system). Version 13, http://www.statsoft.com Available at, http://www.statsoft. com/Products/STATISTICA-Features (Accessed: 15th January 2018) (2016).

28. Rosenberg, N. A. Standardized subsets of the HGDP-CEPH Human Genome Diversity Cell Line Panel, accounting for atypical and duplicated samples and pairs of close relatives. Ann. Hum. Genet. 70, 841-847 (2006).

29. Cann, H. M. et al. A human genome diversity cell line panel. Science 296, 261-2 (2002).

30. Pritchard, J. et al. Inference of Population Structure Using Multilocus Genotype Data. Genetics Society of America. 155, 945-959 (2000).

31. Evanno, G., Regnaut, S. \& Goudet, J. Detecting the number of clusters of individuals using the software STRUCTURE: A simulation study. Mol. Ecol. 14, 2611-2620 (2005).

32. Biswas, S., Scheinfeldt, L. B. \& Akey, J. M. Genome-wide Insights into the Patterns and Determinants of Fine-Scale Population Structure in Humans. Am. J. Hum. Genet. 84, 641-650 (2009).

33. RStudio Core Team. RStudio: Open source and enterprise-ready software for R. R Studio Home Available at, https://www.rstudio. com/, (Accessed: 11th January 2018) (2018).

34. Santos, C. et al. Completion of a worldwide reference panel of samples for an ancestry informative Indel assay. Forensic Sci. Int. Genet. 17, 75-80 (2015).

35. Balloux, F. \& Lugon-Moulin, N. The estimation of population differentiation with microsatellite markers. Mol. Ecol. 11, 155-165 (2002).

36. Ossa, H. et al. Outlining the Ancestry Landscape of Colombian Admixed Populations. PLoS One 11, e0164414 (2016).

37. Manta, F. S. N. et al. Analysis of genetic ancestry in the admixed Brazilian population from Rio de Janeiro using 46 autosomal ancestry-informative indel markers. Ann. Hum. Biol. 40, 94-98 (2013).

38. Weber, J. L. et al. Human Diallelic Insertion/Deletion Polymorphisms. Am. J. Hum. Genet 71, 854-862 (2002).

39. Mills, R. E. et al. An initial map of insertion and deletion (INDEL) variation in the human genome. Genome Res. 9,1182-90 (2006).

40. Gaviria, A. et al. Characterization and Haplotype analysis of 11 Y-STR loci in Ecuadorian population. Forensic Sci. Int. Genet. Suppl. Ser, https://doi.org/10.1016/j.fsigss.2013.10.158 (2013).

41. Gaviria, A. et al. Genetic data for twenty-two autosomal STRs (PowerPlex ${ }_{\oplus}$ Fusion) from Afro-Ecuadorian population. Forensic Sci. Int. Genet. Suppl. Ser. 6, e303-e304 (2017).

42. Gaviria, A. et al. Mutation rates for 29 short tandem repeat loci from the Ecuadorian population. Forensic Sci. Int. Genet. Suppl. Ser. 6, e229-e230 (2017).

43. Gaviria, A. et al. Analysis of the most efficient autosomal strs and genetic data for the locus se33 in ecuadorian population. Forensic Sci. Int. Genet. Suppl. Ser. 5, e93-e95 (2015).

44. Zambrano, A. K. et al. Genetic data of an X-STR decaplex in Ecuadorian population (P). Forensic Sci. Int. Genet. Suppl. Ser. 5, e91-e92 (2015).

45. González-Andrade, F., Roewer, L., Willuweit, S., Sánchez, D. \& Martínez-Jarreta, B. Y-STR variation among ethnic groups from Ecuador: Mestizos, Kichwas, Afro-Ecuadorians and Waoranis. Forensic Sci. Int. Genet. 3 (2009). 
46. Londin, E. R. et al. CoAIMs: A Cost-Effective Panel of Ancestry Informative Markers for Determining Continental Origins. PLoS One 5, e13443 (2010).

47. Shen, C. et al. A 30-InDel Assay for Genetic Variation and Population Structure Analysis of Chinese Tujia Group. Sci. Rep. 6, 36842 (2016).

48. Hoggart, C. J., Shriver, M. D., Kittles, R. A., Clayton, D. G. \& McKeigue, P. M. Design and analysis of admixture mapping studies. Am. J. Hum. Genet. 74, 965-78 (2004).

49. Vásquez, S. L. \& Saltos Galarza, N. Ecuador: su realidad. (Fundación 'José Peralta', 2014).

50. Yang, N. et al. Examination of ancestry and ethnic affiliation using highly informative diallelic DNA markers: Application to diverse and admixed populations and implications for clinical epidemiology and forensic medicine. Hum. Genet. 118, 382-392 (2005).

51. García-García, J. A., Reding-Bernal, A. \& López-Alvarenga, J. C. Cálculo del tamaño de la muestra en investigación en educación médica. Investig. en Educ. Médica 2, 217-224 (2013).

\section{Acknowledgements}

The present study received the support of Laboratorio de Genética of Centros Médicos Especializados Cruz Roja Ecuatoriana; thus, the authors are grateful to all the analysts that were part of the laboratory while the present project was starting. Additionally, the authors are grateful to Rui Pereira.

\section{Author Contributions}

Ana Karina Zambrano: conceived the idea, design, experimental procedure, data analysis and writing. Aníbal Gaviria: conceived the idea, design, experimental procedure, data analysis and writing. Santiago Cobos: experimental procedure. Carmen Gruezo: experimental procedure. Cristina Rodríguez: experimental procedure. Isaac Armendáriz-Castillo: written edition. Jennyfer García-Cárdenas: written edition. Santiago Guerrero: written edition. Andrés López-Cortés: written edition. Paola E. Leone: written edition. Andy Pérez-Villa: writing and formatting. Patricia Guevara-Ramírez: written edition. Verónica Yumiceba: written edition. Gisella Fiallos: experimental procedure. Margarita Vela: experimental procedure. César Paz-y-Miño: coordination and followed up with the development of the article.

\section{Additional Information}

Supplementary information accompanies this paper at https:/doi.org/10.1038/s41598-019-45723-w.

Competing Interests: The authors declare no competing interests.

Publisher's note: Springer Nature remains neutral with regard to jurisdictional claims in published maps and institutional affiliations.

(c) (i) Open Access This article is licensed under a Creative Commons Attribution 4.0 International License, which permits use, sharing, adaptation, distribution and reproduction in any medium or format, as long as you give appropriate credit to the original author(s) and the source, provide a link to the Creative Commons license, and indicate if changes were made. The images or other third party material in this article are included in the article's Creative Commons license, unless indicated otherwise in a credit line to the material. If material is not included in the article's Creative Commons license and your intended use is not permitted by statutory regulation or exceeds the permitted use, you will need to obtain permission directly from the copyright holder. To view a copy of this license, visit http://creativecommons.org/licenses/by/4.0/.

(C) The Author(s) 2019 